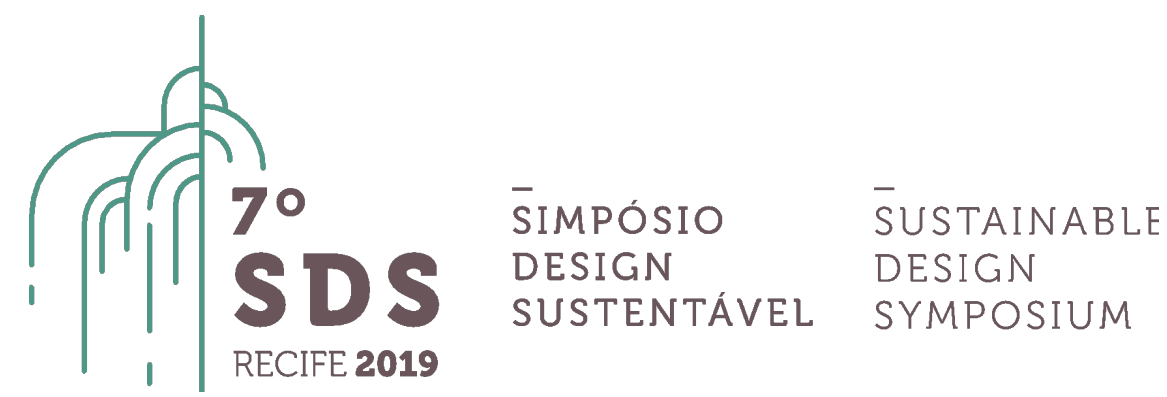

\title{
Social Design: An introduction to brazilian's perspective
}

\author{
Juliana Pontes Ribeiro PhD in Architecture and Urbanism ${ }^{1}$, Adriana Tonani Mazzieiro Master in Architecture and Ur- \\ banism ${ }^{2}$, Gabriel Julian Wendling Cardoso Graphic Design Graduate and Psychology Graduate Student ${ }^{3}$ and Giulia \\ Pereira Brito Design Graduate Student ${ }^{4}$

\footnotetext{
${ }^{1}$ FUMEC University, Faculdade de Engenharia e Arquitetura ---FEA, jpontes@fumec.br

${ }^{2}$ FUMEC University, Faculdade de Engenharia e Arquitetura --. FEA, adrianat@fumec.br
} \\ ${ }^{3}$ FUMEC University, Faculdade de Ciências Humanas --- FCH, gabrielwendling@gmail.com \\ ${ }^{4}$ FUMEC University, Faculdade de Engenharia e Arquitetura --- FEA, giuliapbrito@gmail.com
}

\begin{abstract}
This article discusses the approximations and differences in the processes of Social Design and Social Innovation when developed in Italy and Brazil. The understanding of the local conditions of the contexts in which the actions are materialized is of fundamental importance in order to understand, principally, the difficulties of carrying out design processes in Brazilian communities that result in the transformation of models, practices, products and services recognized as real innovations according to the original concepts of the European tradition. Thus, some case studies from Italy and Brazil have been used to elicit evidence that the susceptibility of successful applications of these theories and methods is largely due to external constraints of a social, cultural, environmental or economic nature.
\end{abstract}

Keywords. Social Design; Social Innovation; Systemic Design; Co-creation; Brazil; Italy.

\section{Introdução}

Ao apontarmos a ideia de localização em um comparativo entre duas cidades situadas em países distintos - Brasil e Itália, pode parecer a sugestão de um trabalho infindável, especialmente se a abordagem fosse por municípios ou microrregiões, mas o que se pretende debater aqui são diferenças específicas entre contextos situados em países com alto estágio de desenvolvimento econômico e social, no caso a Itália, frente a contextos específicos de países em situações mais precárias nesses setores, como o Brasil por exemplo. Assim, as observações locais, na verdade, servem como referências que explicitam como esses aspectos podem interferir na potência de uma ação se configurar como Design Social ou Inovação Social. Portanto, a escolha desses parâmetros territoriais tem como objetivo observar o quanto esses dois modelos operacionais de mediações/interações em comunidades ou agrupamentos sociais, aplicados com perspectivas de renovações em termos econômicos e culturais pela via dos serviços e produtos, podem ser confrontados com obstáculos contextuais, que demandam uma relação dialógica com lógicas e atributos particulares de cada território e, em última instância, com o alicerce socioeconômico, educacional e cultural de cada país. 
O entendimento de Design Social e de Inovação social é fundamental para as discussões teóricas e observações de práticas nesse estudo. Para oferecer suporte ao longo dessa reflexão, surge a necessidade de uma breve explanação sobre esses dois modelos, não no sentido de apresentá-los, mas no sentido de mostrar, em certa comparação, as aproximações e diferenças em seus processos de realização, assim como a suscetibilidade do sucesso de suas aplicações às condicionantes externas de natureza social, cultural, ambiental ou econômica.

O Design Social que, como o nome já diz, aponta para uma ideia de projeto de um mundo mais sustentável, especificamente no sentido de oferecer mais soluções viáveis para as rotinas sociais em todos os seus níveis de limitação econômica. Esse princípio já denota uma democratização do acesso aos produtos e projetos de design, ampliando o entendimento da profissão para além da sofisticação industrial e tecnológica que necessariamente demanda altos investimentos financeiros. Esse conceito tem lastro histórico em décadas passadas, como podemos ver a seguir:

\footnotetext{
O engajamento social de Designers, entretanto, não é algo recente. Ele se inicia com uma reação à sociedade industrial, com o foco especial em Design de produtos mais democráticos. Tal concepção foi denominada de Design Social, entendida como uma abordagem voltada a resolver problemas humanos em larga escala, especificamente na forma de produtos materiais e imateriais. (MARGOLIN apud JOLY, 2015, p. 37)
}

Um aspecto que já pode ser debatido nesse ponto em relação ao conceito de Inovação Social é o diagnóstico do problema cotidiano a ser resolvido. Nos casos em que se configura um projeto de Design Social, comumente o diagnóstico do real problema de Design é feito por profissionais dessa área. Esses designers utilizam técnicas de imersão no contexto observado, entrevistas com a comunidade usuária do futuro projeto e, inclusive, etapas de co-criação após o diagnóstico, além de outros recursos inerentes ao processo criativo do Design, para formalizar as suas propostas de projeto.

Em um contexto que caminha rumo à ideia de Inovação Social, já podemos identificar diferenças sensíveis na etapa de diagnóstico dos problemas coletivos. Um fator primordial nesses momentos iniciais é a percepção de uma demanda bottom-up, ou seja, uma necessidade vivida pelos membros de uma comunidade e percebida por eles mesmos como uma oportunidade potencial de mudanças em suas lógicas de produção e/ou organização social. Sendo assim, uma condição para uma real Inovação Social é o investimento na percepção e na experiência dos próprios usuários, potencializando e desenhando formas de materializar suas ideias e intuições, que são originadas "de baixo para cima". Logo, percebemos a diferença, pois em um projeto de Design Social é possível que uma demanda seja detectada diretamente pela observação dos profissionais da área, assim como a solução pensada, desde que se mantenha uma real conexão com a realidade observada e com as necessidades de diversas naturezas a serem atendidas. Nota- se que dessa forma estamos lidando com a sensibilidade dos designers frente a um contexto social e com sua capacidade propositiva dentro da situação-problema diagnosticada.

Esse ponto é crucial para diferenciar as dinâmicas que levam a um projeto de Design focado em sua Dimensão Social daquelas que conduzem a um contexto amplo de ações que, de forma sistêmica e integrada, podem levar a uma Inovação Social que combina intervenções de Design aliadas a outras iniciativas profissionais. Todas as duas formas de atuar provavelmente envolverão parcerias com setor público, universidades, empresas, organizações não governamentais e outros agentes, mas com aspectos de participações distintas: no Design Social os parceiros podem entrar em momentos específicos e contribuir com partes do processo de forma mais autônoma e pontual; porém, em uma situação de Inovação Social as parcerias devem funcionar de forma mais orgânica e contínua, sendo constituídas de forma integrada ao longo da concretização da proposta. A estratégia de co-criação torna--se fundamental no segundo caso, pois as parcerias se consolidam à medida que concebem, em conjunto, ações sistêmicas em direção a um novo modelo social. Esse debate comparativo já foi abordado por alguns autores: 
Nesse contexto, Manzini (2014d) acredita que design social é referente às atividades projetuais que resolvem problemas pontualmente. Design para a inovação social, por outro lado, refere--se ao projeto em torno de mudanças incrementais ou radicais dos sistemas sociais existentes. Nesse ponto, o intuito é atingir um nível sistêmico, afim de ajustar os sistemas sociais de um determinado contexto, no intuito de torna--los resilientes (MANZINI, 2013). Manzini (2014d) defende que a tendência é que design social se torne uma atividade complementar ao design para a inovação social, enquanto este abrangerá grande parte das atividades futuras de Design voltadas para a sociedade. (MANZINI apud JOLY, 2015, p. 37-38)

Essas observações nos levam a uma aproximação entre o Design Social e as práticas metodológicas já consolidadas na área profissional do Design, apresentando a possibilidade de se mostrar uma alternativa para situações em que a mobilização social ainda não é suficiente para formatar consciências propositivas nos usuários, gerar articuladores de parcerias locais ou uma coesão de objetivos, justamente por não existir uma noção clara de grupo. O Design Social se revela uma intervenção projetual socialmente positiva no sentido de ser centrada na iniciativa do profissional da área e na sua capacidade de diagnosticar, avaliar e conceber soluções focadas em problemas sociais bem delineados. Já as iniciativas que resultam em Inovações Sociais dependem de uma integração de intenções e demandas sociais de um grupo que, ciente de tal condição coletiva, consegue absorver uma rede de parcerias externas dentro de uma malha orgânica de colaborações e benefícios, interagindo com diversos setores e profissionais, dentre esses os designers. Esses últimos interatuam na rede em um processo dinâmico e colaborativo, colocando seus recursos metodológicos como instrumentos em prol do novo contexto que se forma, evitando colocar os seus ideais projetivos como elementos preponderantes no processo. Isso garante a longevidade e a autonomia da rede formada e das novas lógicas sociais geradas nessa malha sistêmica.

Apresentadas essas questões, partimos da premissa de que países com uma coesão social mais frágil, resultante de instituições públicas e governos com pouca capacidade de administrar ações de apoio às iniciativas dos cidadãos organizados e de comunidades; cujos indivíduos possuem baixo índice de consciência de seus laços sociais e comunitários, além de pouca escolaridade para instrumentalizar iniciativas organizadas; e, também, baixo empoderamento social dos cidadãos, apresentam um leque maior de fatores dificultadores quando se trata de implementar propostas bottom-up, que operam em uma lógica sistêmica no intuito de estabelecer algum tipo de inovação social. Nesses cenários, o Design Social consegue mais sucesso em suas empreitadas, pois não depende da superação de um encadeamento de lacunas sociais para realizar benefícios pontuais e de caráter, muitas vezes, emergencial.

A proposta desse artigo, então, é colocar em debate os contextos localizados, que condicionam as diversas ações nessas direções, tentando evidenciar alguns aspectos particulares de cada economia, cultura, território e lógica social que possam favorecer a aplicação do Design Social e/ou da Inovação Social.

Dessa forma, no próximo tópico apresentamos a discussão acerca da rede de profissionais que atuam no contexto da inovação.

\section{Organização social para inovação}

Ao buscar compreender os fatores estruturais de organização social que favorecem o estabelecimento de uma relação sistêmica para a inovação social, a partir de processos bottom-up, esse estudo admite que o Design, nesse contexto, extrapola a dimensão projetual.

Ambos, o Design Social e a Inovação Social acontecem tanto em uma dimensão projetual, no ato de desenvolver soluções criativas para os problemas apresentados, quanto em uma dimensão social, na rede relacional que se dá entre os atores sociais envolvidos. Para que haja uma interseção efetiva entre essas duas dimensões, é necessário que o entendimento permeie além da 
solução pragmática, permitida pelo design, um aprofundamento da dimensão social. É por tal motivo que essas categorias de design carecem de um trabalho interdisciplinar e de uma noção de quem são esses atores. Se o projeto está inserido em um contexto social, ali haverá um grupo de pessoas envolvidas e uma realidade específica. Portanto, vale desenvolver também aprofundamentos teóricos que fundamentem análises empíricas mais consistentes. Usualmente, a totalidade dessa rede se dará entre: a equipe dos profissionais advindos de uma instituição acadêmica interessada no seu desenvolvimento científico, através da parceria e troca com a sociedade civil, em uma relação simbiótica; um conjunto de pessoas particular de uma localidade de interesse, representantes da sociedade civil e com potencialidade de desenvolvimento, podendo ser um grupo menor ou uma comunidade inteira; outras entidades, como organizações governamentais de fomento a esse desenvolvimento. É preciso demarcar algumas características dos componentes dessa rede.

Primeiramente, quem são esses profissionais acadêmicos que estão projetando a ação social? Assim sendo, ao se falar de Design Social ou Design para a Inovação Social, designers irão constituir essa equipe. Ademais, para compor um pensamento sistêmico íntegro, há que se contar com uma equipe multidisciplinar, no intuito de se compreender a dimensão social da realidade. Não é sempre possível executar projetos com esse nível de interdisciplinaridade, contando com a participação de diferentes departamentos acadêmicos, mas não se pode esperar que o designer seja devidamente preparado para aquilo que esses outros profissionais se especializaram.

\begin{abstract}
Hoje sabemos que as questões que colocamos não podem ser consideradas como o reflexo puro de uma realidade objetiva, mas como o resultado da elaboração de formas históricas de percepção e representação dessa realidade. Especialmente nas ciências humanas, ao elaborar nossas questões de pesquisa, baseamo-nos muito mais nessas representações, mediadas pelas características do contexto sociocultural onde operamos, que propriamente em percepções objetivas e neutras do mundo no qual vivemos. (CAMPOS E GUARESCHI, 2014, p. 8)
\end{abstract}

Em segundo lugar, portanto, qual é o perfil desse grupo da localidade de interesse, com potencial de desenvolvimento, do qual a Academia se aproxima e propõe a simbiose? O presente artigo se interessa aqui pelo contexto latino-americano, onde se dá a aplicação de conceitos de Design Social e Design para Inovação Social advindos de outra realidade, a europeia, com uma metodologia científica liderada por Manzini $(2002,2008,2015)$ e outros autores em sintonia de pensamento. Percebemos, que na América Latina, outras abordagens possam se mostrar mais representativas dos contextos locais, sendo estas constituídas por aspectos mais qualitativos baseados em uma matriz interacionista dialética (CAMPOS E GUARESCHI et al, 2014). Isso possivelmente acarreta a necessidade de uma adaptação metodológica mais condizente com o funcionamento desta sociedade. Ou seja, se a metodologia de design originária for aplicada ao contexto em questão, sem adaptação e sem uma análise crítica de como ela o impacta e é por ele impactada, existe o risco de que o processo se dê de maneira não satisfatória. Isso se ocorre uma vez que, são as próprias pessoas que determinam até onde o design pode impactar suas vidas e se realmente querem promover mudanças em sua realidade, ainda que as demonstrações da metodologia pragmática do design ilustrem uma versão material melhorada de sua realidade. 0 design pode trazer a solução material para problemas sociais, mas é a sociologia que vai entender o que acarreta estruturalmente esses problemas, e é a psicologia que vai permitir reconhecer a subjetividade humana daqueles que os vivenciam. É necessário, portanto, compreender esse o contexto latinoamericano, sobretudo brasileiro, sua identidade e suas peculiaridades gerais, além das ideologias e crenças que o perpassam.

Diante dessa outra matriz cultural, as ciências sociais indicam a seleção de metodologias capazes de interagir com tais complexidades, como a pesquisa participante e a pesquisa-.-ação, esta última definida como:

[...] um tipo de pesquisa social com base empírica que é concebida e realizada em estreita 
associação com uma ação ou com a resolução de um problema coletivo e no qual os pesquisadores e os participantes representativos da situação ou do problema estão envolvidos de modo cooperativo ou participativo. (THIOLLENT, 2011, p. 20)

Por outro lado, alguns autores e correntes teóricas podem ser utilizados como arcabouço que sustente análises interpretativistas, como a teoria da estruturação de Giddens (1999) que busca compreender a relação entre agência humana e estrutura social; a praxiologia de Bourdieu $(1989,1990)$ que propõe a superação de dicotomias entre agência e estrutura, sujeito e objeto, objetivo e subjetivo; a teoria culturalista de Reckwitz (2002); a ontologia do lugar de Schatzki (1997); a arqueologia e genealogia de Foucault $(1981,1987,2003)$ que apresenta a reflexão sobre saber, poder e ordem discursiva; a teoria do ator-rede de Latour (1994) que defende a dimensão social como a interação entre atores humanos e não-humanos, a exemplo da tecnologia, ou, ainda, as práticas cotidianas como modos de ação, como operações realizadas pelo indivíduo no processo de interação social descritas por Certau (2008).

Por último, organizações governamentais se dispõem ao fomento a esse desenvolvimento social. Elas completam a rede de atores sociais envolvidos no processo de Design Social ou Design para Inovação Social, com a disponibilização de recursos advindos do setor público. Mas essas ações provenientes da categoria institucional terão pouco efeito se não operarem na direção do design sistêmico demandado para o alcance da inovação social. O caminho necessário para o desenvolvimento de ações que considerem essas relações sistêmicas já se apresenta delineado e espera--se que, com a maturidade de processos de Design Social, consiga--se criar condições favoráveis para o alcance dos cenários almejados, via uma melhor unificação entre essas dimensões projetuais e psicossociais, centradas na inovação social.

\section{Análise comparativa de casos entre Belo Horizonte e Torino}

Ainda que bem definidos os conceitos de Design Social e Design para a Inovação Social, nota--se uma diferença na aplicação desses conceitos entre países em desenvolvimento e desenvolvidos, uma vez discutidas neste artigo, questões que se relacionam à organização social do contexto latino-americano e também brasileiro.

Nesse viés, ao iniciarmos o que pode se desenvolver em uma análise entre estudos de casos europeus e latino--americanos, de maneira a visualizar a presença da inovação social em suas conclusões teóricas e práticas, foi possível notar algumas particularidades e diferenças entre cada local analisado. Com o foco de apresentar tais diferenças, escolheu-se analisar quatro estudos de caso nos quais o Design Social com viés sistêmico foi executado: dois brasileiros, especificamente localizados na cidade de Belo Horizonte, tendo sido um deles acompanhado pela própria equipe deste artigo, e, dois europeus, realizados na cidade de Torino, na Itália. Constatamos semelhanças, mas, principalmente, pontos de distinção quanto aos resultados pela ótica da inovação social.

\subsection{Casos italianos}

Os estudos de caso italianos se dividem em dois projetos - Turin Social Innovation e Tell + Write - cada um em conjunturas distintas: o primeiro mais focado na melhora do funcionamento de algumas áreas da cidade italiana de Torino e, o segundo, um planejamento de produtos e estratégias para reerguer um fabricante de canetas em situação crítica de mercado.

Turin Social Innovation foi realizado por estudantes e professores do Instituto Politécnico de Torino (Politecnico di Turin) e estabeleceu-se como uma plataforma digital com um plano de inovação social subdividido em cinco projetos, com uma média de quatro alunos no comando de cada. O objetivo era atender às demandas de cinco áreas com vivências sociais diferentes. Isso 
posto, o projeto foi realizado em três partes: pesquisa, design e a execução de cada projeto em si. A plataforma une a participação acadêmica com o ingresso de empresas e instituições colaboradoras para o seu funcionamento.

A parte de pesquisa envolveu investigações quantitativas e qualitativas acerca dos aspectos econômicos, políticos e sociais de cada distrito da cidade para que assim, na etapa de design, fossem elaboradas propostas de certa forma globais, mas que ainda assim atendessem às complexidades locais, gerando inovação social.

Em suma, foram realizados planos de um site que melhorasse a interação dos ciclistas com a cidade, pictogramas que tornassem mais fácil a comunicação entre estrangeiros - turistas e imigrantes - de países diferentes, novas estratégias de mercado para reverter a situação do desperdício de comida, conscientização e reparação da poluição juntamente com a escassez de áreas verdes e, por fim, uma integração entre instalações esportivas por meio de site e aplicativo visando serviços mais acessíveis para os habitantes.

Destaca-se aqui o que acreditamos que possa vir a ser um ponto em comum entre os projetos que aplicam a metodologia do design sistêmico em países desenvolvidos. Numa primeira instância, percebemos um maior investimento de tempo, além de recursos econômicos, no plano, possibilitando o envolvimento de um grupo maior de pessoas para a execução efetiva da teoria do design sistêmico na criação de inovação social. Outro ponto a ser levantado é, como consequência desses investimentos, uma criação de "produtos" muito práticos e, ainda assim, com grande complexidade, para atender a questões específicas de características locais muito bem definidas, alcançando um resultado mais positivo no quesito da consolidação da inovação social prática.

Quanto ao outro projeto italiano, o planejamento sistêmico foi utilizado, dessa vez, de maneira a constituir a inovação de produto na parte de comunicação de uma empresa de canetas já consolidada no mercado - a Storilinea, que encontrava-se em fase de crise, reafirmando a teoria da metodologia sistêmica e se encaixando na inovação em diversos âmbitos do design, não apenas o social.

O projeto desenvolveu-se primeiramente por meio de uma análise feita pelos estudantes de design em conjunto com os funcionários e o CEO durante meses, de forma a estudar e compreender o processo de produção das canetas da marca, dos materiais utilizados, do mercado promocional e do envolvimento dos consumidores com o produto.

The results outcome was innovative not only terms of style but especially to the level of meaning about the use, the communication and the interaction of the users with a promotional pen. Tell + Write pens are innovative because they are transferring the message through their shapes, their functional characteristics and new production strategies without introducing new assets in the company, but just reuse them in other way. (GAIARDO E TAMBORRINI, 2015, p.9-10) ${ }^{1}$

Após três conceitos diferentes de canetas criados pelos alunos, a empresa desenvolveu o conceito final: a caneta Bella!, que possuía características pontuais e importantes de outros conceitos que foram sugeridos durante o processo de criação. Em sua forma final, o produto se caracterizava como objeto colecionável que continha uma estética que criasse a impressão de várias canetas diferentes em uma só, além de ser produzida para escrever em papel, com a ponta trocável para ser utilizada em dispositivos móveis.

These two experiences have led us to experiment our methodology in two different cases

\footnotetext{
${ }^{1}$ o resultado foi inovador não apenas em termos de estilo, mas especialmente no nível de significado sobre o uso, a comunicação e a interação dos usuários com uma caneta promocional. As canetas Tell + Write são inovadoras porque estão transferindo a mensagem através de suas formas, suas características funcionais e novas estratégias de produção sem introduzir novos ativos na empresa, mas apenas reutilizando--os de outra maneira." Tradução nossa.
} 
of innovation. The first one, in an academic environment where starting from the territory the aim was to enhance the value in order to introduce a social valuable innovation. The second one, in a company environment, where starting from the know-how and production asset we were challenged to looking for a formal and innovative concept in a market sector characterized by stagnation and crisis of ideas. ${ }^{3}$ (GAIARDO E TAMBORRINI, 2015, p.12)

A experiência citada acima nos leva a crer que a metodologia sistêmica quando aplicada de modo a desenvolver o produto final (dentro do objetivo de inovação social ou não), se mostra mais eficaz ao ter uma execução por um maior prazo de tempo, mas principalmente, ao dialogar com as demandas dos beneficiados durante todo o procedimento, fazendo deles participantes e não só receptores do processo de inovação social.

\subsection{Casos brasileiros}

O primeiro caso permeia a construção de uma oficina de chá para idosos sob a justificativa de estabelecer uma ligação entre o bem-estar para o idoso e o paisagismo produtivo ${ }^{2}$, gerando uma inovação na rotina das chamadas Instituições de Longa Permanência para Idosos (ILPI). EscoIhida uma ILPI de Belo Horizonte para a realização do experimento, adotou--se o critério sistêmico a partir de uma pesquisa qualitativa, utilizando a técnica de pesquisa-ação para compreender a complexidade das relações sociais dos idosos entre si e com os funcionários de uma instituição. A seguir, desenvolveu--se uma oficina com duas etapas, sendo a primeira um momento de confraternização em formato de "chá da tarde" para a interação entre idosos, pesquisadoras e funcionários da ILPI, somada ao "resgate de conhecimentos sobre chás, espécies vegetais conhecidas e seus benefícios, plantio, além de outras memórias que foram despertadas." (BASTANI E POSSAS, 2016, p.3301). A segunda etapa passou pelo plantio de fato das ervas que geram os chás, acompanhado de uma instrução aos idosos sobre o cultivo das plantas, com o objetivo de gerar um paisagismo produtivo. Ao final de todo esse processo, as pesquisadoras chegaram à seguinte conclusão:

Foi percebido que os colaboradores da instituição receberam a oficina de chás, como um evento pontual, mas não entenderam a importância da continuidade da atividade do cultivo. Concluiu--se que essa situação derivou da incompreensão da proposta de melhoria do bem-estar, que para ser alcançado continuamente após o dia da oficina, necessita de estímulo e acompanhamento dos idosos com os cuidados das plantas. (BASTANI E POSSAS, 2016, p.3304).

De acordo com as pesquisadoras que comandaram a ação, seria necessário reafirmar a importância da oficina para o bem-estar dos idosos, bem como a utilidade de uma equipe de continuadores que pudessem acompanhar as ações na instituição, oferecendo auxílio nos cuidados diários com as ervas. Assim, feitos os ajustes, "[...] acredita--se que essa atividade tem o potencial para gerar uma inovação social, se aplicados em rede à várias instituições." (BASTANI e POSSAS, 2016, p.3304).

Levando em conta os resultados alegados pelas pesquisadoras, suspeita--se aqui da presença de algumas características provavelmente comuns aos casos brasileiros: a necessidade de melhores condições de tempo e investimento para preparar as propostas com cada agente envolvido, em um projeto que passe pelo design sistêmico. Ainda que plantada uma importante semente de inovação social com a oficina, é perceptível a ausência de partes do conceito sistêmico na execução, considerando que a ação sistêmica precisa ter uma lógica cíclica, que deve ser repetida várias vezes para a consolidação da inovação. Seria interessante uma investigação de deman-

\footnotetext{
${ }^{2}$ Paisagismo produtivo pode ser definido como: “[...] produção de alimento associada a fatores da vida urbana e abrange campos como a cultura, o lazer, a saúde, o bem-estar e a geração de renda. É uma prática que vai além da produção de espécies para consumo: visa às relações, tanto entre os praticantes, como desses com a percepção de aspectos da natureza." (NAHUM apud BASTANI; POSSAS, 2016, p. 3299)
} 
da dos idosos participantes visando um efeito bottom-up, colocando-os como agentes ativos do contexto para que, junto da preparação dos funcionários da IPLI acerca do projeto, consiga--se uma oficina que possa progredir ainda mais quanto à qualidade de vida dos idosos, em um projeto com trocas de conhecimentos e práticas que podem ser compartilhados futuramente até mesmo com a sociedade em geral.

Ainda apresentando casos brasileiros, o segundo caso passa pelo programa de extensão da Universidade Fumec intitulado Cerne: Design, Arquitetura, Artesanato e Arte. A extensão, em uma parceria com o SEBRAE-MG e com a associação Lá da Favelinha da periferia urbana do aglomerado da Serra, em Belo Horizonte, criou a coleção de roupas e acessórios Remexe 2 a partir do upcycling, de forma a objetivar atividades que alcancem benefícios culturais, sociais e também ambientais. Para a realização das atividades foram pensadas soluções de caráter sistêmico que passam pela interdisciplinaridade, em uma via de mão dupla, na qual haja um intercâmbio entre os conhecimentos acadêmicos e populares.

Dentro dessa proposta, para a fundamentação teórica da estrutura do projeto procurou-se por bibliografias especializadas na área do Design Social, principalmente nos anais do 12 을 Congresso Brasileiro de Pesquisa e Desenvolvimento em Design, realizado em 2016 em Belo Horizontes, Minas Gerais. Foram encontrados diversos artigos que levantavam o valor da participação da Universidade nas aplicações do conceito de Design Social, bem como as redes de apoio à inovação LASIN (Rede Latino--Americana de Inovação Social) e DESIS (Design para Rede de Inovação Social). Dentro do contexto brasileiro, as Universidades são importantes agentes de disseminação dos conceitos de Design Social e de Inovação Social, nas iniciativas fundamentadas em pesquisas e em projetos de extensão junto às comunidades nas quais desenvolvem esses projetos.

A princípio, o método para o desenvolvimento da coleção Remexe 2 passou por um mapeamento sensorial e fotográfico e o reconhecimento dos conceitos geradores da coleção Remexe 1, realizada anteriormente. Não menos importante, também foi efetuada uma etapa de revisão bibliográfica e coleta de dados através de técnicas qualitativas de pesquisa. Esse estudo foi realizado de forma etnográfica e também imersiva não participativa. Questões sobre o conceito e aplicação do upcycling foram investigadas de acordo com o perfil contemporâneo do consumidor. Tudo foi feito de modo a tentar compreender melhor as demandas do grupo de beneficiários e criar roupas e acessórios que se encaixassem na realidade dos habitantes do Aglomerado da Serra.

No decorrer da ação, além da capacitação dos beneficiários, foram preparados e oferecidos workshops curtos a fim de disponibilizar o conhecimento social e as tecnologias geradas no projeto para o público geral. A produção da coleção Remexe $\mathbf{2}$, utilizou roupas doadas e resíduos sólidos, trouxe para si o conceito das curvas presente em todo o ambiente urbano da região por meio de processos co-criativos entre alunos e beneficiários. Tais processos se sucederam em oficinas de upcycling que, com a intenção de capacitar as costureiras do aglomerado da serra, foram divididas em: personalização, serigrafia, tie--dye, bordados e produção. O resultado foi visto com a caracterização individual das roupas por meio de estampas tipográficas e bordados à mão. Como resultado final, além da produção de catálogos e cartazes, elaborou--se um editorial de moda com as peças da coleção vestindo os moradores do aglomerado (apresentados na peça editorial como modelos). Um desfile realizado dentro das instalações da própria Universidade FUMEC também fez parte do resultado final.

Podemos afirmar então que existem, sim, aspectos positivos no âmbito socioambiental de toda a ação, uma vez que os objetivos do projeto foram alcançados. Entretanto, a experiência nos faz levantar a questão de uma possível dependência do Design Social com as universidades, sendo essas os principais agentes de iniciativas na área dentro dos países latino--americanos. Tal ponto, porém, não é necessariamente negativo, já que o envolvimento acadêmico na prática pode impulsionar o seu crescimento e propagação, de forma a consolidar novas metodologias que consigam a 
implantação com êxito da Inovação Social.

\section{Design Social e Inovação Social no contexto brasileiro}

Ao aprofundar o conhecimento sobre os casos apresentados, nota-se aproximações e diferenças nos processos de Design Social e de Inovação Social quando desenvolvidos na Itália e no Brasil. O entendimento das condições locais dos contextos nos quais as ações de Design Social e de Inovação Social foram materializadas é de fundamental importância para que se compreenda, principalmente, as dificuldades de se efetivar processos de design em comunidades brasileiras que resultem em transformações de modelos, práticas, produtos e serviços reconhecidos como reais inovações de acordo com os conceitos originais da tradição europeia.

Quanto às aproximações nos estudos de casos dos dois países, identifica--se que: os processos criativos que levam à resultados de Inovação Social surgem, essencialmente, de processos bottom-up, assumindo maior legitimidade social e, portanto são mais duradouros; os processos são mais profundamente consolidados se existem equipes multidisciplinares trabalhando em conjunto com as comunidades diretamente afetadas pelos processos de design, introduzindo as abordagens sistêmicas necessárias aos processos de inovação; os processos onde existe a participação das Universidades são facilitados, e resultam mais comumente em Inovações Sociais, dada à possibilidade de maior imersão em análises, metodologias, técnicas e processos criativos colaborativos baseados em abordagens sistêmicas. Estes aspectos são observados nos casos da cidade de Torino e do Projeto Cerne, onde as universidades, Politécnico de Torino e a Universidade Fumec, possuem equipes multidisciplinares atuando junto a comunidades com um grau maior de coesão social e identidade de grupo. Claro que esta última característica citada, de uma comunidade criativa $^{3}$ já pré-existente, mesmo incipiente e cheia de problemas de diversas naturezas, assume papel importante no sucesso dos projetos de Design para a Inovação Social, pois a maturidade de grupo já significa uma terra fértil na qual os processos de design podem germinar.

No âmbito das diferenças identifica-.-se que, dadas às diversas condições sociais, culturais, econômicas e ambientais encontradas no Brasil, que aumentam a dificuldade de se ter coesão social nas comunidades, os processos de criação coletivos não são entendidos pelos grupos criativos e se perdem com o tempo, na ausência de um agente promotor constante que desempenhe 0 papel de agente agregador e organizador das ações, o que em si já representa um problema estrutural nos processos, pois o designer deve ser um agente em conjunto com a comunidade, não um agente promotor da comunidade. As necessidades básicas das comunidades brasileiras estão longe de estarem resolvidas, o que no contexto de processos criativos, de acordo com nossa experiência, pode acarretar em algumas consequências não muito positivas, como falta de tempo, cansaço dos participantes e, ao final, desinteresse causado pelo tempo de espera para que se tenha retornos palpáveis e de longo alcance. Existe também a dificuldade de se conseguir uma equipe multidisciplinar capaz de interagir com a comunidade e de compreender toda a complexidade dos processos de Inovação Social, o que, no caso da Itália percebe--se constituir--se mais facilmente.

Nos estudos de caso são citados quem são os atores sociais e o nível de interação que se deu entre eles. Isso confirma a existência de uma estrutura organizacional favorável à inovação, um grupo de atores sociais respectivos às instituições e comunidades de origem, que permitiu a implementação do Design Social ou do Design para Inovação Social, tanto no contexto latino-americano, quanto no europeu. Ou seja, há então elementos básicos que compõem o ato projetual de design, mas também há aqueles que compõem a dimensão social com a qual ele se intersecta. É perceptível nesses casos não só uma diferença de nível sistêmico como social. Nos casos eu-

\footnotetext{
${ }^{3}$ O conceito de Comunidade Criativa adotado é o conceito cunhado por Meroni que a considera como um grupo de pessoas que, de forma colaborativa, inventam, aprimoram e gerenciam soluções inovadoras para novos modos de vida. (MERONI, 2007)
} 
ropeus, houve como processo determinante, que foi a utilização da tecnologia para resolver o problema posto. Nesses lugares, a relação funcionalista com o digital e uma malha industrial mais avançada fundamenta uma base e promove um caminho mais determinista, com estreita relação com o positivismo. Percebe--se que induzindo a mudança da relação das pessoas com o próprio processo, colocando-as num estado mais próximo com a tecnologia, a inovação ocorre via utilização da própria estrutura técnica.

Já nos casos latino-americanos, há uma abordagem bem diferente, feita primariamente através da malha social e não da tecnológica. O que se deu ali foi a indução de novas formas de relacionamento entre os participantes dos projetos, mas apenas feita com um cuidado mediante as relações que já estavam postas e o entendimento crucial acerca da identidade daquelas pessoas. Só após essa estreita aproximação cultural ocorreram transformações permitidas pelo ato projetual, que promoveu a organização das pessoas em direção à resolução do problema. Houve muito mais uma adaptação social criativa ao modelo sociológico demonstrado, do que uma evolução tecnológica. As pessoas aprenderam novas formas de se fazer algo, tendo que desenvolver novas habilidades criativas, ao invés de se basear em estrutura técnica já posta e a fazê-la progredir. A mudança foi mais de caráter comportamental em relação ao meios de produção disponíveis e não tanto uma mudança de avanço tecnológico. Isso confirma a proposição psicossocial de que no contexto latino-americano existe uma matriz cultural de qualidades criativas e autorenováveis. Montero (2014, p. 74) retrata as peculiaridades do ator social latino-americano, o colocando em situação ótima para trabalhar no modelo interacionista e com a metodologia da pesquisa--ação:

[...] se trata de alguien que posee conocimientos y que continuamente los produce; por lo tanto es alguien que piensa, actúa y crea, cuyo conocimiento, conocido como conocimiento popular, es fundamental tener en cuenta. Por eso, al considerar que tal sujeto participa en el trabajo e investigación comunitaria, está sumando a ellos su saber a la vez que interviene en la construcción de otros nuevos: nuevo conocimiento científico y nuevo conocimiento popular. Es también un sujeto que critica, actúa y reflexiona desde la propia realidad que construye, a partir del discurso y de las acciones. ${ }^{4}$ (MONTERO, 2014, p.74)

É a partir da valorização da capacidade social e criativa peculiar do latino--americano que a Inovação Social se dará de maneira mais intensificada, contrastando com uma expectativa de inovações que viriam da malha tecnológica, mais defasada nesse contexto se comparada a dos países desenvolvidos. Em países em desenvolvimento e com uma cultura tão rica em formas sociais como a do Brasil, é interessante formalizar os esforços da pesquisa junto ao que justamente este povo tem de característica forte: sua criatividade e maleabilidade perante à vida.

\section{Conclusão}

Apesar da identificação de desafios que dificultam a existência de processos de inovação no Brasil, consegue--se encontrar iniciativas que levam a cabo ações de Inovação Social em uma perspectiva transformadora.

Percebe--se que, para que processos de Inovação Social no Brasil consigam ter mais efetividade, deve--se identificar comunidades criativas que tenham maior nível de coesão social, um exercício mais difícil para os designers que, de uma maneira mais comum, praticam processos de Design Social em comunidades carentes, mas não necessariamente criativas no sentido de or-

\footnotetext{
4 "Se trata de alguém que tem conhecimento e os produz continuamente; portanto, é alguém que pensa, age e cria, cujo conhecimento, conhecido como conhecimento popular, é essencial se levar em conta. Portanto, ao considerar que tal sujeito participa de trabalhos e pesquisas comunitárias, está agregando seus conhecimentos a eles enquanto intervêm na construção de novos: novos conhecimentos científicos e novos conhecimentos populares. É também um sujeito que critica, age e reflete a partir da realidade que constrói, a partir de discursos e ações". Tradução nossa.
} 
ganizadas para a reinvenção colaborativa da sua dinâmica social. A criatividade e a inventividade existem, mas em múltiplas iniciativas individuais ou isoladas. Não que as práticas de Design Social não possuam relevância, elas ocupam um importante espaço de resolução de problemas, mas seus efeitos a longo prazo são pequenos e, em muitos casos, se perdem com o tempo, pois não alteram de forma essencial e fundamental a vida das pessoas, nem as suas relações sociais, econômicas e ambientais. Não criam uma nova mentalidade, uma cultura que contamine todos os aspectos da vida da comunidade e as modifique definitivamente.

Uma conclusão possível a partir dessa constatação aponta, então, para a necessidade de identificação de possíveis comunidades criativas já pré-existentes para que, a partir delas, entendidas como potências legítimas das comunidades, se possa trabalhar com o design gerando resultados viáveis de Inovações Sociais. Uma segunda conclusão é o reconhecimento de que agentes diversos podem estar em conjunto trabalhando nas comunidades com equipes multidisciplinares, que constituem o conteúdo conceitual importante para o entendimento da complexidade existente em processos de Inovação Social, interagindo e colaborando entre si e com a comunidade com suas diversas formações, sejam elas acadêmicas, profissionais ou institucionais. $E$, finalmente, observa--se o surgimento de diversas iniciativas, no Brasil e no mundo, que estão preconizando o mesmo tipo de pensamento sobre a atuação do campo de conhecimento do Design nas comunidades, o que tem fortalecido, cada vez mais, este pensamento sistêmico e complexo a respeito das ações que desenvolvem Inovações Sociais duradouras, transformando o mundo em que vivemos. O que definitivamente é um avanço nateoria e nas práticas sociais, econômicas e ambientais.

\section{Referências}

AMILTON, A.; OLIVEIRA, A. R. M.; FILHO, I. G. C.; SILVA, P. R. Design e os processos de inovação social como agentes transformadores em comunidades criativas. In: AMILTON, A. (org.). Design e Inovação Social. São Paulo: Blutcher, 2017.

BASTANI, K.R; POSSAS, D. de C. Design sistêmico para inovação social: A construção de uma oficina de chá para idoso. In: Blucher Design Proceedings, 2., Belo Horizonte, 04 a 07 out. 2016. Anais do 12을 Congresso Brasileiro de Pesquisa e Desenvolvimento em Design. Belo Horizonte, 2016. p.3295-3307.

BOURDIEU, P. O poder simbólico. Lisboa, Difel, 1989.

BOURDIEU, P. (1990) The Logic of Practice. Cambridge: Polity Press.

CAMPOS, R. H. de F. GUARESCHI. Apresentação. In: CAMPOS, R. H. de F.; GUARESCHI, P.;

CERTEAU, Michel: A invenção do cotidiano: 1. Artes de fazer. Petrópolis: Vozes, 2008.

FOUCAULT, M. Ordem do discurso. São Paulo: Loyola, 2003.

FOUCAULT, M. Palavras e as coisas. São Paulo: M. Fontes, 1981.

FOUCAULT, Michel. Vigiar e punir: nascimento da prisão. Petrópolis: Vozes, 1987.

GAIARDO, A.; TAMBORRINI, P. Systemic innovation design methodology: The comparison of two cases studies. In: The Value of Design Research, Paris, 22 a 24 abr. 2015. 11th European Academy of Design Conference Proceedings. Paris: Descartes University, 2015.

GIDDENS, Anthony; TURNER, Jonathan (orgs.). Teoria Social Hoje. São Paulo: Ed.Unesp, 1999. p. 393-446.

HAXELTINE, A. ; KEMP. R.; DUMITRU, A.; AVELINO, F.; PEL, B.; WITTMAYER, J.M. A First Prototype JOLY, M. P. Design para Inovação Social e a Rede DESIS no Brasil. 2015. 246 f. Dissertação (Mes- 
trado) -- Curso de Programa de Pós-graduação em Engenharia de Produção, Coppe, Universidade Federal do Rio de Janeiro, Rio de Janeiro, 2015.

LATOUR, Bruno. 1994 [1991]. Jamais fomos modernos: ensaio de antropologia simétrica. Rio de Janeiro: Editora 34.

MANZINI, E. \& VEZZOLI, C. O Desenvolvimento de Produtos Sustentáveis: Os Requisitos Ambientais dos Produtos Industriais. São Paulo: Edusp, 2002.

MANZINI, E. Design para a inovação social e sustentabilidade: comunidades criativas, organização colaborativas e novas redes projetuais. Rio de Janeiro: E--papers, 2008.

MANZINI, E. Design, When Everybody Designs: An Introduction to Design for Social Innovation.

MASSIMI, M.; MONTERO, M.; et al. Paradigmas em Psicologia Social: A perspectiva latino--americana. 6. ed. Petrópolis, RJ: Vozes, 2014.

MASSIMI, M. Matrizes de Pensamento em Psicologia Social na América Latina. In: CAMPOS, R. H. de F.; GUARESCHI, P.; MASSIMI, M.; MONTERO, M; et al. Paradigmas em Psicologia Social: A perspectiva latino-americana. 6. ed. Petrópolis, RJ: Vozes, 2014.

MERONI, A. 2007. Creative Communities: People inventing sustainable ways of living. Milano, Edizioni Polidesign, 182 p. Disponível em: www.sustainable--everyday.net. Acesso em: 2019.

MONTERO, M. Construcción, Desconstrucción, y Crítica: Teoria y Sentido de la Psicologia Social Comunitaria en America Latina. In: CAMPOS, R. H. de F.; GUARESCHI, P.; MASSIMI, M.; MONTERO, M.; et al. Paradigmas em Psicologia Social: A perspectiva latino--americana. 6. ed. Petrópolis, RJ: Vozes, 2014.

of Transformative Social Innovation Theory. TRANSIT Deliverable 3.2, TRANSIT: EU SSH.2013.3.2-1 Grant agreement no: 613169, 2015.

PAPANEK, V. Design for the Real World. 2. ed. Chicago: Academy Chicago Publishers, 2009.

RECKWITZ, Andreas. Toward a theory of social practices: a development in culturalist theorizing. European Journal of Social Theory. Londres: Sage Publications, p.243-263, 2002.

SCHATZKI, T. (1997) Practices and action: A Wittgensteinian Critique of Bourdieu and Giddens, Philosophy and the Social Science, 27(3): 283-308.

SHEA, A. Design For Social Change: strategies for community-mbased graphic design. New York: Princeton Architectural Press, 2012.

The MIT Press, 2015.

THIOLLENT, M. Metodologia da pesquisa-ação. 18. ed. São Paulo: Cortez, 2011.

WALKER, S. The Spirit Of Design: objects, environment and meaning. New York: Earthscan, 2011. 